\title{
Análisis de la información disponible en Google Maps de los servicios turísticos de Río Gallegos. Santa Cruz
}

\section{Analysis of available information on tourist services of Rio Gallegos on Google Maps}

\author{
Carlos Andrade, Alicia Pompeya Caceres, Patricia Frias \\ carlos.andrade.94@hotmail.com,acaceres@uarg.unpa.edu.ar,pfrias@uarg.unpa.edu.ar \\ Universidad Nacional de la Patagonia Austral, Unidad Académica Río Gallegos \\ Santa Cruz, Argentina \\ Escuela de Turismo
}

Recibido: 01/06/2020. Aceptado: 17/11/2020

\begin{abstract}
RESUMEN
El siguiente informe corresponde a las obligaciones de la cátedra de Metodología de Investigación, de la carrera de Licenciatura en Turismo, año académico 2018, en la UNPAUARG. Tiene por objetivo analizar la información sobre los servicios de alojamiento, gastronomía y de agencias turísticas de la ciudad de Río Gallegos disponibles en la herramienta Google Maps.

La plataforma de la marca estadounidense, es una de las más utilizadas por los usuarios, tanto en lo cotidiano como también a la hora de viajar a otro destino. Además de cumplir la función de un mapa y de guiar y ayudar al usuario en materia de localización, le facilita la búsqueda de servicios.

En la herramienta de Google Maps, llamada Google My Business, el empresariado local puede gestionar su propio perfil de servicio, incluyendo fotografías, o información relacionada con horarios, medios de comunicación, tarifas, etc. Pero esa interactividad permite también que los usuarios puedan cargar contenido y emitir opiniones, para valorizar los servicios.

Metodológicamente se completaron fichas de relevamiento que tienen en cuenta variables como la cantidad de usuarios que votan, valoración promedio, presencia de fotografías, tipo de fotografías, verificación de la cuenta y demás.

Los resultados aportan una valoración buena y muy buena de servicio por parte de los usuarios, aunque existen cantidades desproporcionadas devotos $\mathrm{y}$ opiniones entre establecimientos del mismo tipo de servicio.
\end{abstract}

Palabras clave: TICs; Google My Businnes; Interactividad.

\begin{abstract}
This report has the objective to analyze the information about accommodation services, gastronomy and tourist agencies in the city of Río Gallegos available on Google Maps.

The famous platform of American brand Google is one of the most used by users, in everyday life and also when travelling to another destination. In addition to fulfilling the function of a map, it facilitates the search of services.

In the Google Maps tool called Google My Business, the local business can manage their own service profile, including photographs, or information related to schedules, means of
\end{abstract}


communications, rates, etc. The interactivity of this platform allows users upload content and issue opinions, also valuing services.

Through surveys that take into account variables such as the number of users who vote, average rating, type of photographs, verification of account, etc., 22 hotels, 18 restaurants and 5 travel agencies are analyzed.

The results provide a good and very good assessment of service by users, although there are disproportionate amounts of opinions among establishments of the same type of service.

Keywords: ICT4D; Google My Business; Interactivity.

\section{INTRODUCCION}

Las tecnologías de la información y comunicación (TICs) están en un continuo avance, y lo que ayer era novedoso, quizás mañana ya no lo será. El turismo es una actividad que consiste en el desplazamiento de las personas hacia lugares distintos al de su entorno habitual, y donde la información es el insumo base, siendo internet es el principal canal de búsqueda de información.

Por estas razones es indispensable la presencia de los destinos y de los servicios, exhibiendo su oferta, en la red, y que sea de forma eficiente, de forma que puedan impactar la mayor cantidad de usuarios posibles.

Herramientas como Google Maps permiten a los servicios estar al alcance de los turistas 3.0, convirtiéndose en una oportunidad de captarlo e influir en sus decisiones.

Río Gallegos cuenta con una gran cantidad de servicios en lo que respecta a hotelería, la gastronomía y en menor medida las agencias turísticas. En poco tiempo cualquier usuario navegando en Google Maps en la ciudad de Río Gallegos, puede encontrar los servicios y visualizar como los usuarios los valoran mediante un sistema de puntuación de estrellas y leer las reseñas que algunos usuarios comparten. Además, pueden observar la información del servicio en sí, como características que posee, horarios, medio de contacto, tarifas, etc.

El siguiente informe da a conocer la valoración actual de los servicios turísticos de la ciudad según la información proporcionada por la plataforma Google Maps.

El objetivo general es conocer la situación actual sobre los servicios turísticos de Río Gallegos a través de la información publicada en Google Maps.

El objetivo específico es relevar información de los servicios turísticos de Río Gallegos publicados en Google Maps, para efectuar un análisis acerca de con qué frecuencia e importancia utilizan la plataforma los servicios de la ciudad capital.

\subsection{Marco Teórico}

\section{MARCO DE REFERENCIA}

La constante evolución de las Tecnología de la Información y la Comunicación (TICs) y el potencial de impacto global que poseen como característica, las han transformado en una necesidad fundamental a cubrir en la industria turística.

En la actualidad no existen barreras para el intercambio de información. La localización de quien la produce y de quienes la perciben no es un impedimento. Las nuevas tecnologías permiten el acceso a la información a tiempo real, y sin tener en cuenta las distancias, ni la localización.

Para encaminarse a conseguir resultados óptimos en la gestión de un destino o producto turístico, es imprescindible contar con las TICs como una herramienta fundamental, que 
además nos de proporcionar información, también se convierten en canales para la distribución de las mismas (Pachón, 2014).

Así como cambian las tecnologías constantemente con la creciente e imparable digitalización del mundo, cambia también el turista, al que se conoce como "turista 3.0". La característica fundamental del viajero moderno es que ve el mundo a través de su smarthphone. Se encuentra conecta en la red y forma parte de las comunidades, donde busca la información, la comparte y además opina (Ledhesma, 2017).

Cuando se habla de un turista 3.0 se habla de un turista colaborativo. Los usuarios o los potenciales clientes se han convertido en la imagen de las marcas y de los productos. El participar de forma activa en las distintas comunidades online (redes sociales), les confiere un poder para decidir y una voz, que al expresarse se transforma en un foco de atención para otros potenciales clientes.

Por esta razón, los distintos negocios turísticos deben cubrir la mayor cantidad de canales de comunicación posibles, para hacerse visible para el turista y cualquier usuario en general. Aquí aparecen herramientas del marketing digital como lo son las redes sociales, algunas consolidadas como Facebook, Twitter y más temprano en el tiempo, Instagram. Todas poseen distintos tipos de públicos, y características propias que permiten difundir información que puede resultar de interés y de utilidad para los usuarios.

Cuando se habla de turismo, una aplicación (app) clave es Google Maps, desarrollada desde 2005 por Google, la app ${ }^{1}$ consiste en un servidor de mapas. Entre sus funciones principales, proporciona mapas desplazables, fotografías satelitales, imágenes $360^{\circ}$ a pie de calle (Google Street View), condiciones de tráfico en tiempo real (Google Traffic), herramientas de cálculo de tiempo en rutas a pie, en auto o transporte público y un navegador GPS. La plataforma perteneciente a la multinacional estadounidense reemplaza elementos del turismo convencional como los mapas.

Las funciones mencionadas anteriormente son las más trascendentes, pero no son las únicas. Existe una función dentro de Google Maps denominada "Google My Business". Esta herramienta está dirigida a las empresas para que aumenten su visibilidad en línea, fortaleciendo su presencia en internet y la confianza de los clientes (Google Support). La visibilidad de la información es vital en la industria turística, y para el desarrollo de los servicios principales que la integran, para así captar a los turistas 3.0.

Los servicios turísticos comprenden el conjunto de actividades perfectamente diferenciadas entre sí, pero íntimamente relacionadas, que funcionan de manera coordinada para satisfacer las necesidades de la corriente turística (Cavassa, 2008). Esto incluye a los servicios de desplazamiento (transporte, agencias de viaje), los que satisfacen necesidades básicas como descanso y alimentación (alojamiento y restauración), y las atracciones turísticas.

Entre la información que puede exhibirse del negocio, pueden publicarse fotografías, sitio web, teléfono, ubicación, horario, y en algunos casos tarifas o accesos directos a reservas o compras de servicios. Además, Google My Business permite la interacción con los usuarios, que pueden escribir reseñas sobre su experiencia con la empresa.

Otra característica de interés es el sistema de valoraciones de Google, donde los usuarios puntúan con estrellas el servicio o negocio. Las calificaciones oscilan desde una estrella hasta cinco.

Los propietarios de las distintas empresas pueden visualizar el número de visitas que ha tenido su negocio, como también las búsquedas y obviamente los distintos comentarios, lo cual es de gran utilidad al momento de realizar análisis para medir el impacto de la información disponible en los usuarios.

\footnotetext{
${ }^{1}$ Abreviatura de application, que hace referencia a una aplicación móvil, es decir un programa, pero con características específicas, de fácil instalación y uso. Por ejemplo, las redes sociales son apps. Google Maps, también.
} 


\subsection{Marco histórico-geográfico}

El análisis se centrará sobre distintos servicios turísticos que son ofrecidos en la ciudad de Río Gallegos. La ciudad surge fines de 1885, es la capital de la provincia de Santa Cruz, la más austral de la Argentina continental.

Si sitúa en el extremo sureste de la provincia, en el área costera Fig.1. Según el censo de población de 2010 del INDEC, Río Gallegos registró 95.796 habitantes, lo que la ubica como el municipio con más habitantes de las 15 localidades de la provincia.

Se encuentra comunicada por las rutas nacionales $\mathrm{N}^{\circ} 3$, paralela a la costa atlántica, y por la $\mathrm{N}^{\circ} 40$ con el interior provincial, paralela a la cordillera. Posee un aeropuerto internacional, con vuelos diarios a Buenos Aires, y otros destinos con frecuencia varias como Ushuaia y Comodoro Rivadavia. Además, constituye el último punto de apoyo continental de las comunicaciones con Antártida y las Islas Malvinas (Cáceres et al., 2016).

Fig. 1. Localización de la ciudad de Río Gallegos

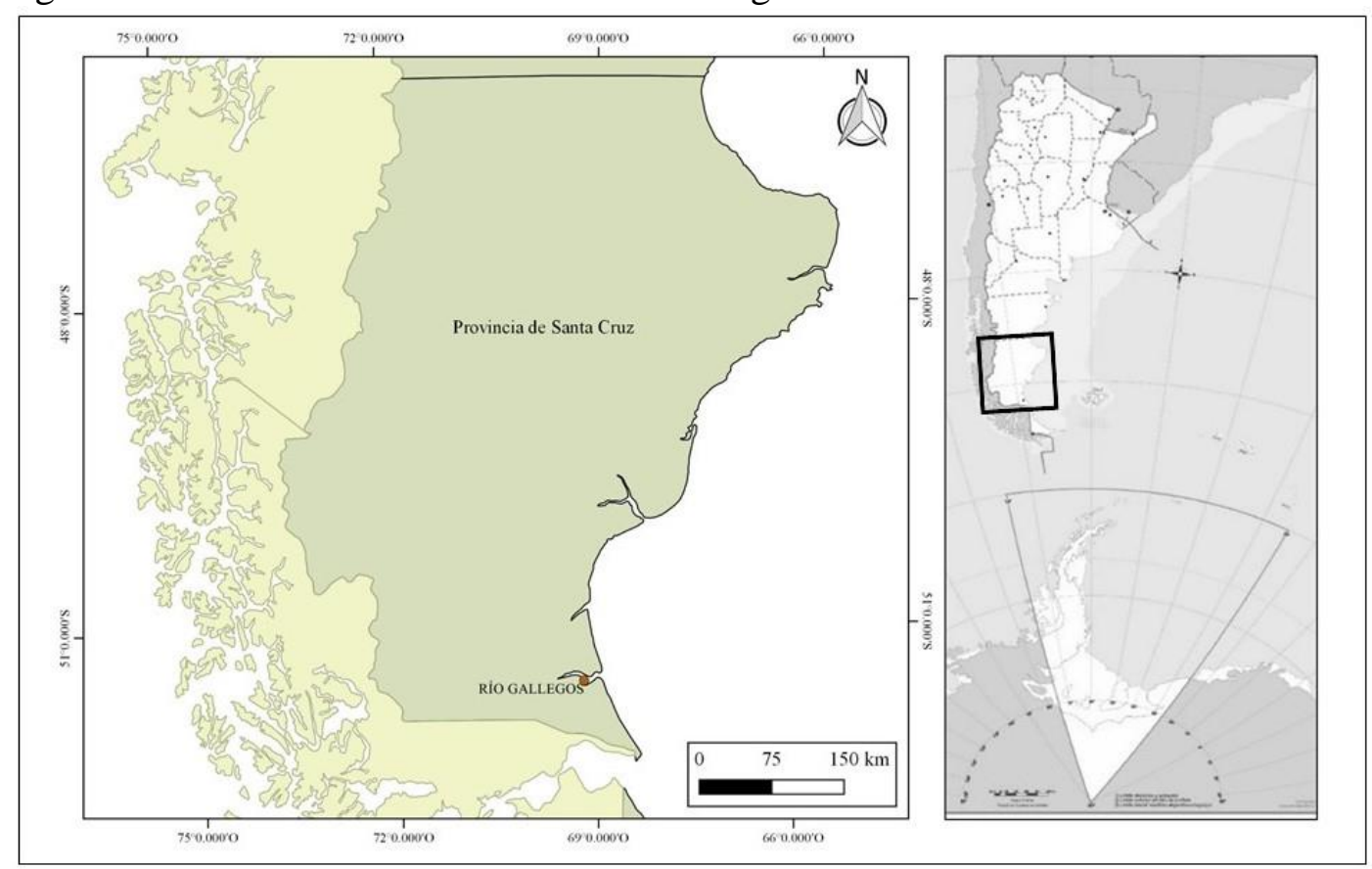

Fuente: Cáceres et al, 2016:51

En lo que respecta al turismo, la ciudad de Río Gallegos se considera un centro de escala, aunque en el pasado se lo señalaba como un centro de distribución. El cambio de rol fue consecuencia de la inauguración del aeropuerto de El Calafate en el año 2000 que permitió el aterrizaje de aviones con gran capacidad de pasajeros, que en el pasado arribaban a la ciudad capital (Ampuero et al, 2015 en Cáceres et al, 2016;58).

Al ser Río Gallegos la capital provincial, posee una función política administrativa, lo que requiere una complejidad de servicios (Cáceres et al, 2016).

\section{METODOLOGÍA}

El presente informe requirió de la búsqueda de información bibliográfica acerca de la temática y de las herramientas Google Maps y Google My Business, además de antecedentes previos que hayan abordado la misma problemática. No se encontraron estudios similares al propuesto en el presente informe, lo que influyó en la decisión de definir y analizar las variables que la misma herramienta de Google exhibe, así como utilizar sus criterios de valoración. 
Para analizar los servicios turísticos se tomó en cuenta aquellos relacionados con el alojamiento, la gastronomía y las agencias de viaje. No se incluyó los servicios de transporte y atracciones urbanas como los museos, debido al tiempo requerido para realización del informe. En el caso de la gastronomía solo se tuvo en cuenta a la categoría de restaurantes, y no así bares o rotiserías, por la misma razón mencionada anteriormente.

Para orientar la búsqueda de los servicios en Google Maps y su posterior relevamiento, se utilizó la base de datos que realiza la Dirección de Turismo de la Municipalidad de Río Gallegos, a fecha de segundo semestre de 2018.

Para organizar la información recogida se diseñó una ficha para cada conjunto de servicios, sin criterio de orden (ver anexo). Posteriormente se propuso otro modelo de ficha, las cuales resultaron adecuadas; cabe aclarar que los relevamientos fueron realizados entre el 2 y 5 de noviembre de 2018.

Para todos los tipos de servicios se tomó en cuenta algunas variables comunes como, por ejemplo: cantidad de usuarios que calificaron el servicio, y la valoración promedio. Para ambas variables fue aplicada una medición con nivel de intervalo de referencia. A continuación, se detalla:

Cantidad de usuarios que calificaron: se clasificó en intervalos según el número que votaron al servicio en:

1. Más de 500

2. Desde 400 a 499

3. Desde 300 a 399

4. $\quad$ Desde 200 a 299

5. Desde 100 a 199

6. Desde 50 a 99

7. Desde 1 a 49

Valoración según usuarios: se utilizó la explicación que utiliza Google My Business, que utiliza una escala de 1 a 5 estrellas, entendiendo por 1 como un servicio malo, 2 como regular, 3 como bueno, 4 como muy bueno y 5 como excelente. Explicación de la puntuación (según Google)

8. 5 estrellas: "Me ha encantado"

9. 4 estrellas: "Me ha gustado"

10. 3 estrellas: "Está bien"

11. 2 estrellas: "No me ha gustado"

12. 1 estrella: "No me ha gustado nada"

Entre otras variables analizadas, por ejemplo, para el alojamiento, se decidió observar los canales de reservas añadidos al perfil de Google de la empresa.

La presencia o no de fotografías ha sido una de las variables comunes analizadas en todos los servicios, así como si poseen el número de teléfono añadido al perfil, una página web y si las cuentas están verificadas, lo cual significa que la gestión del perfil la realiza la propia empresa.

\subsection{Alojamiento}

\section{RESULTADOS Y DISCUSION}

En lo que respecta a la categoría de servicios de alojamiento, fueron analizados 22 establecimientos: 17 hoteles, 2 hosterías y 3 apart hotel. El Hotel que más cantidad de usuarios han valorado ha sido el Hotel Patagonia, con 436 votantes (a fecha de análisis), 
mientras que el Apart Retamar registró 10 votantes, siendo éste el establecimiento con menor cantidad de votos.

Según los intervalos de referencia mencionados anteriormente, sólo 2 establecimientos han tenido al menos 300 votantes, y 5 han tenido más de 200. Los 15 alojamientos restantes han tenido menos de 200 usuarios que los han calificado. (Figura 2)

Fig. 2. Cantidad de usuarios que han calificado

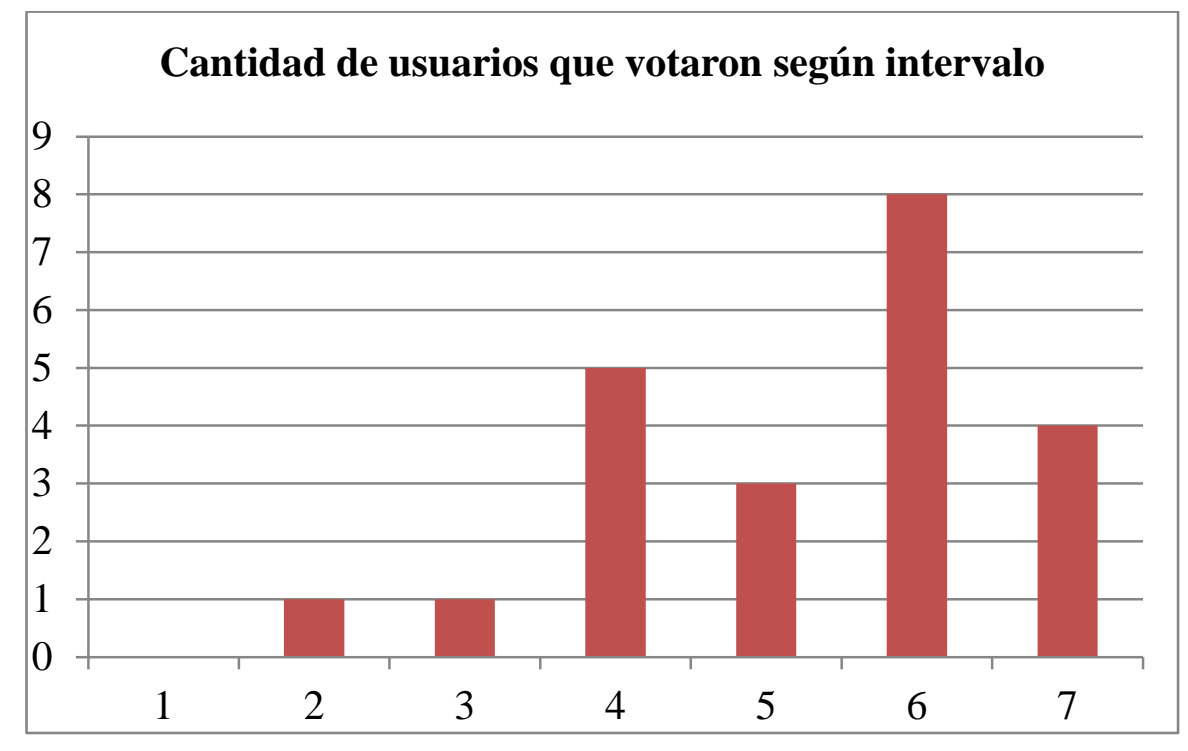

De los 22 alojamientos analizados, 14 han tenido una calificación mayor a 3 y menor a 4, calificándose como "bueno". Los 8 establecimientos restantes se califican como "muy bueno" debido a su valoración promedio mayor a 4.

De los 22 hoteles, 21 poseen imágenes en su perfil de Google Maps. 20 hoteles incluyen al menos una imagen de las habitaciones (interiores). Además 20 de los 22 hoteles, incluyen su número de teléfono, lo cual es muy importante, ya que es una variable clave para utilizar dentro la herramienta de Google.

En lo que respecta a los canales de reserva, 18 hoteles poseen al menos un servidor dentro del perfil de Google Maps que redirecciona al usuario a consultar disponibilidad y efectuar una reserva. El $66 \%$ utiliza Booking.com, que es el canal de reserva más repetido por sobre otros como Despegar (sólo en 3 casos) u otros canales. (Figura 3)

Fig. 3. Canales de reservas añadidos.

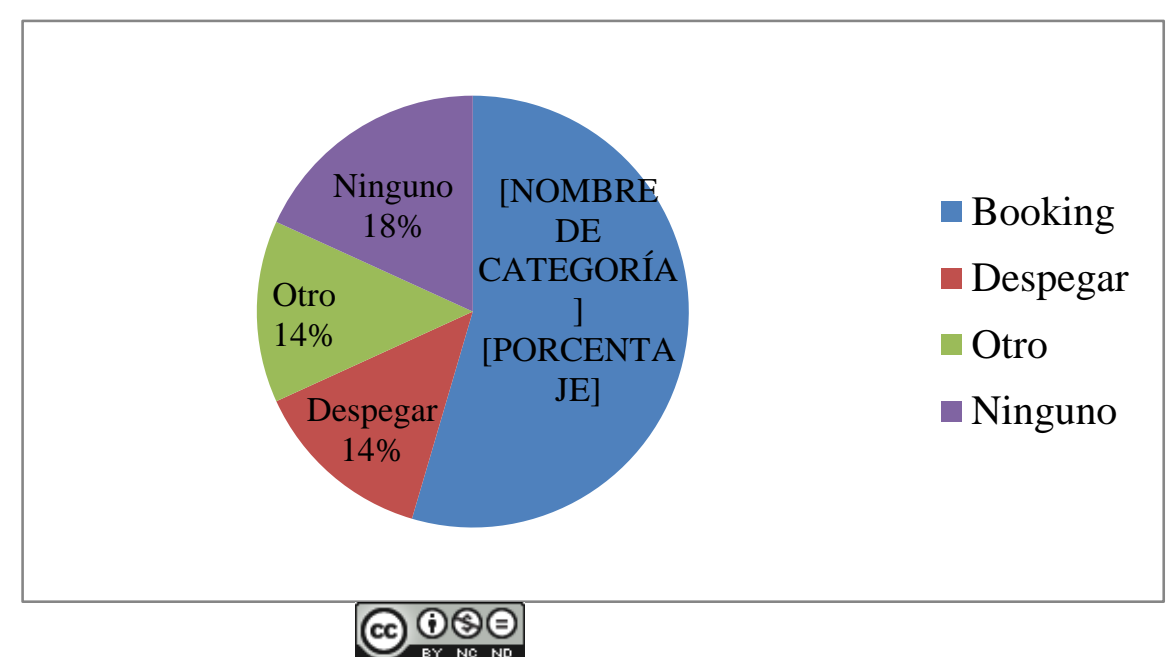


Existen 16 alojamientos que poseen su cuenta verificada, es decir, que están registradas en Google My Business, por lo que gestionan sus propios perfiles.

\subsection{Gastronomía}

Han sido analizados 18 restaurantes de la ciudad de Río Gallegos, los cuales todos poseen presencia en Google Maps. Cabe destacar que solo 10 poseen cuenta verificada en Google My Business.

En lo que respecta a la valoración promedio, 14 restaurantes tienen una calificación mayor a 4 estrellas, por lo que se los clasifica con un "muy bueno". Existe una mayor cantidad de usuarios votantes que en la categoría alojamiento, lo cual es normal si tenemos en cuenta que los servicios de gastronomía son prestados a menudo a los residentes locales. Se contabilizan 5 establecimientos con al menos 300 usuarios votantes, estacando el caso de "Mini Winery and Deli", el cual posee más de 600 votantes.

A excepción de 2 casos, los demás restaurantes poseen imágenes de algunos de los platos que ofrecen. Debe tenerse en cuenta que en varias oportunidades son los propios usuarios quienes las comparten las imágenes. Se destaca el restaurant "Neneo", el cual realiza publicaciones dentro de su perfil publicando las novedades diarias, como las promociones o menú del día, etc.

\subsection{Agencias}

Un total de 5 agencias han sido analizadas. La situación en lo que respecta a las agencias de viaje es totalmente distinta a los servicios anteriores. Sólo una cuenta está verificada, y sólo 3 han sido calificadas por usuarios, siendo el número de los mismos menor y perteneciendo al intervalo de referencia 7 (menos de 50).

Aquella cuenta verificada de la agencia "Essenya" es la única que posee fotografías, y también es la única que posee teléfono y página web añadida.

En síntesis, la presencia de los servicios turísticos de la ciudad de Río Gallegos en Google Maps puede calificarse como satisfactoria, en lo que respecta al alojamiento y a los restaurantes.

Todos los establecimientos de los rubros mencionados se encuentran presentes en Google Maps, y de 40 servicios analizados, 26 poseen cuenta verificada, es decir, que están registrados en Google My Business. Esto demuestra un interés y una preocupación por aprovechar la oportunidad que la plataforma de Google ofrece de exhibirse como servicio, y poder tener un mejor monitoreo de la interacción con los usuarios.

Cabe destacar que el tener cuenta verificada no garantiza tener mayor valoración que los servicios que si la tienen.

La presencia en la red, es una necesidad a cubrir, y estar presentes en la mayoría de los canales de comunicación puede generar mayor número de visitas, interacciones, y también de expectativas según el contenido publicado, pero eso no garantiza que un servicio sea de calidad.

La presencia de fotografías, tanto externas como internas, de las habitaciones en el caso de los alojamientos y de platos de menú en los restaurantes, se convierten en un valor agregado, ya que al encontrarse añadidas en un perfil de servicio en Google Maps, el cual es de fácil navegabilidad, permite generarle una idea al usuario que está visitando de lo que puede llegar a encontrarse.

Los números de teléfono o webs añadidas también ayudan en el caso de contacto, y se ha podido observar que la mayoría de los perfiles tienen añadido al menos el número de teléfono. 
Una situación distinta presenta las agencias de viaje y turismo. Es cierto que los servicios de alojamiento y de gastronomía son más utilizados, y por lo tanto más buscados y comentados por parte los usuarios en las redes, y Google Maps no es la excepción. Pero se ha observado a través del relevamiento poca preocupación por parte de los propietarios de las agencias.

Si bien, queda claro, que un servicio no es mejor que otro por estar presente en Google Maps, o por la cantidad de comentarios de usuarios que comentan, no puede subestimarse el poder que tiene la plataforma de mapas el cual, con una buena gestión del perfil, puede captar clientes al estar presente de forma eficiente en una de las apps más utilizadas en la industria turística.

\section{CONCLUSIONES}

Como conclusión, el objetivo "analizar la información sobre los servicios de alojamiento, gastronomía y de agencias turísticas de la ciudad de Río Gallegos disponibles en la herramienta Google Maps", se ha cumplido.

Los resultados de este informe, aportan tanto desde lo teórico como metodológico para estudios de la actividad turística, similares o posibles actualizaciones, en relación a la valoración de servicios por parte de los usuarios, sea en la plataforma Google Maps, u otro tipo de herramientas digitales, que en la industria turística crecen en su importancia año a año, principalmente debido a las interacciones con turistas reales y potenciales.

\section{BIBLIOGRAFIA}

AMPUERO, C; LA VALLE, M; CÁCERES, A. (2015). Etapas de crecimiento urbano de El Calafate (1927-2010). Boletín de Estudios Geográficos № 105. Facultad de Filosofía y Letras - UNCu Mendoza.

CÁCERES, A., SEGOVIA STANOSS, M., SOTO, J., NORAMBUENA, M., FRIAS, P., AMPUERO, C. (2016). "Posición geográfica de Río Gallegos en la Patagonia Austral". UNPA - UARG.

CAVASSA, C. (2008). "Calidad total en las empresas turísticas". México.

LEDHESMA, M., SILVA, M. (2017). “Travel blogger y Turismo 3.0”. Ciudad Autónoma de Buenos Aires.

GOOGLE. "Ayuda de Google My Business". (2018) Recuperado de: https://support.google.com/business\#topic=4539639

PACHÓN, M. G. (2014). "Impacto de las TICs en el sector turístico". Universidad de Valladolid. 


\section{Fichas de relevamiento}

\section{ANEXOS}

\section{Alojamiento}

\begin{tabular}{|c|c|c|c|c|c|c|c|c|c|c|c|c|}
\hline & & & \multicolumn{2}{|c|}{ 1. Canales de reservas } & \multirow{2}{*}{\multicolumn{2}{|c|}{$\begin{array}{l}\text { Cantidad de usuarhtervalos } \\
\text { que votaron: }\end{array}$}} & \multirow{2}{*}{\multicolumn{2}{|c|}{$\begin{array}{l}\text { Valoración promedio } \\
\text { según usuarios: }\end{array}$}} & \multicolumn{4}{|c|}{ 4. ¿Posee imáge 5. Imágenes exter } \\
\hline ID & Nombre & Bookin: & Despeg & Otro & & & & & SI & NO & SI & NO \\
\hline$\overline{\mathrm{A} 01}$ & Aire de Patagonia & & $x$ & & 210 & 4 & \begin{tabular}{|c|}
4.1 \\
\end{tabular} & Muy Buend & $x$ & & $x$ & \\
\hline A0द्व & \begin{tabular}{l|l} 
Alonso \\
\end{tabular} & $x$ & & & 88 & 6 & 3.5 & Bueno & $x$ & & $x$ & \\
\hline$\overline{\mathrm{AO}} \mathrm{O}$ & Amerian & $x$ & & $X$ (Hoteles.com; Expedia; Drbitz. & 110 & 5 & 4.0 & Muy Buend & $x$ & & $x$ & \\
\hline A04 & Apart Austral & $x$ & & & 267 & 4 & 4.2 & Muy Buend & $x$ & & $x$ & \\
\hline $\overrightarrow{\mathrm{A}} 0 \mathrm{G}$ & Avellaneda & & & & 59 & 6 & 3.9 & Bueno & $\bar{x}$ & & $x$ & \\
\hline$\overline{\mathrm{A}} \mathrm{OA}$ & Cabo Virgenes & $x$ & & & 129 & 5 & 3.5 & Bueno & $x$ & & $\bar{x}$ & \\
\hline$\overline{\mathrm{A} 0 \mathrm{~T}}$ & Colonial & & & & 31 & 7 & 3.5 & Bueno & $x$ & & & $x$ \\
\hline$\overline{\mathrm{A}} \mathrm{O} \mathbb{\mathrm { q }}$ & Comercio & $\mathrm{x}$ & $x$ & & 335 & 3 & 4.1 & Muy Buend & $x$ & & $\bar{x}$ & \\
\hline$\overline{\mathrm{A}} \mathrm{O}$ 羊 & Croacia & & & & 75 & 6 & 4.2 & Muy Buend & $x$ & & $x$ & \\
\hline A10 & El Viejo Miramar & & & & 44 & 7 & 3.8 & Bueno & $x$ & & $\bar{x}$ & \\
\hline A11 & Elcira Hostal & & & & 52 & 6 & 3.8 & Bueno & $x$ & & $x$ & \\
\hline A12 & LaPosada & $x$ & & & 80 & 6 & 3.5 & Bueno & $x$ & & & $\bar{x}$ \\
\hline A13 & Laguna Azul & $x$ & & $X$ X(Hoteles.com; Expedia; Drbitz. & 64 & 6 & 3.3 & Bueno & $x$ & & $x$ & \\
\hline$\overline{\mathrm{A} 14}$ & Latinos & & & & 17 & 7 & 3.1 & Bueno & $x$ & & & $x$ \\
\hline A15 & Liporaci & $x$ & & & 223 & 4 & 3.8 & Bueno & $x$ & & $\bar{x}$ & \\
\hline$\overline{\mathrm{A} 16}$ & Oviedo & $x$ & & & 80 & 6 & 3.5 & Bueno & $x$ & & $\bar{x}$ & \\
\hline A17 & Paris & $x$ & & & 190 & 5 & 3.2 & Bueno & $x$ & & $x$ & \\
\hline A18 & Patagonia & $x$ & $x$ & $X($ FindHotel $)$ & 436 & 2 & 4.3 & Muy Buend & $\bar{x}$ & & $\bar{x}$ & \\
\hline A19 & Punta Arenas & & & & 88 & 6 & 3.6 & \begin{tabular}{|l|} 
Bueno \\
\end{tabular} & $x$ & & $x$ & \\
\hline A20 & Retamar & & & & 10 & 7 & 4.6 & Muy Buend & & $x$ & & \\
\hline A21 & Santa Cruz & & & & 289 & 4 & 4.0 & Muy Buend & $x$ & & $\bar{x}$ & \\
\hline$\overline{\mathrm{A} Z 2} \overline{\mathrm{C}}$ & Sehuén & $x$ & & & 242 & 4 & 3.9 & Bueno & $x$ & & $x$ & \\
\hline
\end{tabular}

\begin{tabular}{|c|c|c|c|c|c|c|c|c|}
\hline 6. Im & es in & $\mathbf{N} \mathbf{d}$ & fono & 3. Pá & veb & & Verfic & 10. Observaciones \\
\hline SI & NO & SI & NO & St & NO & Si & NO & \\
\hline$x$ & & $x$ & & & $x$ & $x$ & & \\
\hline$x$ & & $x$ & & $\bar{x}$ & & & $\bar{x}$ & \\
\hline$x$ & & & $\mathrm{x}$ & $x$ & & & $x$ & En Google Street View se ve el establecimiento aún en construcción \\
\hline$x$ & & $x$ & & $x$ & & $\bar{x}$ & & \\
\hline$x$ & & $x$ & & & 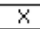 & $x$ & & No posee ningún canal de reserva añadido al perfil \\
\hline$x$ & & $\bar{x}$ & & $\bar{x}$ & & $\bar{x}$ & & \\
\hline$x$ & & $x$ & & & $\bar{x}$ & & $\bar{x}$ & No posee ningún canal de reserva añadido al perfil. Las fotografías añadidas las han subido usuarios (algunas erróne \\
\hline$x$ & & $x$ & & & $\mathrm{x}$ & $\bar{x}$ & & Posee fotografías en $360^{\circ}$ \\
\hline & $\mathrm{x}$ & $\bar{x}$ & & & $\mathrm{x}$ & & $\mathrm{x}$ & No posee ningún canal de reserva añadido al perfil. Las fotografías añadidas las han subido usuarios. \\
\hline $\mathrm{x}$ & & $\mathrm{x}$ & & & $\mathrm{x}$ & $\mathrm{x}$ & & Posee un video añadido por el hotel publicitando el mismo. No posee ningún canal de reserva añadido al perfil. \\
\hline $\mathrm{x}$ & & $\mathrm{x}$ & & $\bar{x}$ & & $\mathrm{x}$ & & Solo un par de fotos añadidas por el hotel. Algunas imágenes son erróneas. No posee canal de reserva an̂́adido. \\
\hline$x$ & & $x$ & & & $\mathrm{x}$ & & $\mathrm{x}$ & \\
\hline$x$ & & $x$ & & & $x$ & $\bar{x}$ & & \\
\hline $\mathrm{x}$ & & & $\bar{x}$ & & $\mathrm{x}$ & & $\bar{x}$ & Las fotografías existentes las han subido usuarios. No posee ningún canal de reserva añadido al perfil. \\
\hline $\mathrm{x}$ & & $\mathrm{x}$ & & & $\mathrm{x}$ & $\bar{x}$ & & \\
\hline$x$ & & $x$ & & $\mathrm{x}$ & $\mathrm{x}$ & $x$ & & \\
\hline$x$ & & $x$ & & $x$ & & $x$ & & \\
\hline$x$ & & $\mathrm{x}$ & & $\mathrm{x}$ & & $x$ & & \\
\hline$x$ & & $\mathrm{x}$ & & & $\bar{x}$ & $x$ & & No posee ningún canal de reserva añadido al perfil. \\
\hline & & $x$ & & & $x$ & $x$ & & No posee ningún canal de reserva añadido al perfil. \\
\hline $\mathrm{x}$ & & $\mathrm{x}$ & & $\mathrm{x}$ & & $\mathrm{x}$ & & No posee ningún canal de reserva añadido al perfil. \\
\hline$x$ & & $\mathrm{x}$ & & $\mathrm{x}$ & & $\mathrm{x}$ & & \\
\hline
\end{tabular}

\section{Gastronomía}

\begin{tabular}{|c|c|c|c|c|c|c|c|c|c|}
\hline & 2. & Cantidad de usuar & htervalo: & Valoración prome & dio & 4. Imá & exte & Imá & inte \\
\hline ID & 1. Nombre & que votaron: & & según usuarios: & & SI & NO & SI & $\mathrm{NO}$ \\
\hline G01 & A.M.S.A & 209 & 4 & 4.3 & Muy Bueng & $x$ & & $x$ & \\
\hline $\mathrm{GOC}$ & Bartolo & 313 & 3 & 4.1 & Muy Buend & $x$ & & $x$ & \\
\hline G03 & British Club & 259 & 4 & 4.3 & Muy Buend & $x$ & & $x$ & \\
\hline G04 & Buffalo Grill & 222 & 4 & 4.1 & Muy Buend & $x$ & & $x$ & \\
\hline $\mathrm{GOS}$ & Comercio Hotel & 41 & 7 & 4.2 & Muy Buend & $x$ & & $x$ & \\
\hline $\mathrm{GOH}$ & Chino Tenedor Libre & 13 & 7 & 4.2 & Muy Buend & $x$ & & & $x$ \\
\hline $\mathrm{GOH}$ & ElCapricho & 28 & 7 & 4.4 & Muy Buend & $x$ & & $x$ & \\
\hline G0A & El Tablón & 148 & 5 & 4.3 & Muy Buend & $x$ & & $x$ & \\
\hline G09 & LaLechuza & 407 & 2 & 3.8 & Bueno & $x$ & & $x$ & \\
\hline G10 & Lihuén & 103 & 5 & 4.6 & Muy Buend & $x$ & & $x$ & \\
\hline G11 & Matamora & 33 & 7 & 3.7 & Bueno & $x$ & & $x$ & \\
\hline G12 & Maximus & 142 & 5 & 4.0 & Muy Bueng & $x$ & & $x$ & \\
\hline G1: & Mini Winery \& Deli & 602 & 1 & 4.2 & Muy Bueng & $x$ & & $x$ & \\
\hline $\mathrm{G} 14$ & Moma & 281 & 4 & 3.8 & Bueno & $x$ & & $x$ & \\
\hline G15 & Neneo & 400 & 2 & 4.2 & Muy Buend & $x$ & & $x$ & \\
\hline $\mathrm{G} 16$ & Pizza Express & 378 & 3 & 3.8 & Bueno & $x$ & & $x$ & \\
\hline G17 & Puerto Macá & 123 & 5 & 4.2 & Muy Buend & & $x$ & $x$ & \\
\hline G18 & Volver & 8 & 7 & 4.1 & Muy Buend & & $x$ & $x$ & \\
\hline
\end{tabular}




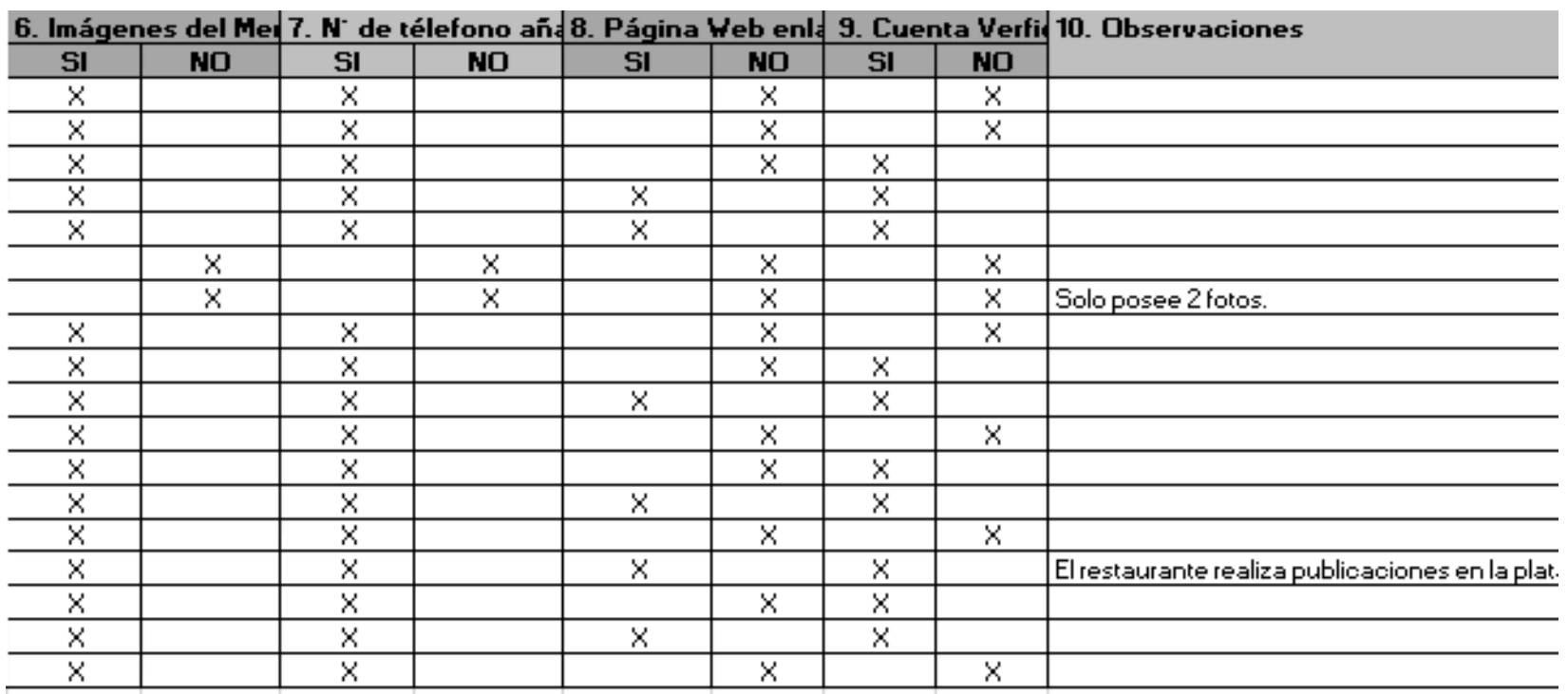

\section{Agencias}

\begin{tabular}{|c|c|c|c|c|c|c|c|c|c|}
\hline & \multicolumn{3}{|c|}{ 2. Cantidad de usuarintervalo } & \multirow{2}{*}{\multicolumn{2}{|c|}{ Valoración promedio }} & \multicolumn{4}{|c|}{ 4. ¿Posee imágel 5 . N de teléfono añ } \\
\hline ID & 1. Nombre & que votaron & & & & SI & NO & SI & NO \\
\hline $\mathrm{v} 01$ & AppianLine Tour & 0 & 0 & 0 & Sin Calficacion & & $x$ & & $x$ \\
\hline $\mathrm{vod}$ & \begin{tabular}{|l|l} 
Essenya \\
\end{tabular} & 15 & 7 & 4.1 & Muy Bueno & $x$ & & $x$ & \\
\hline vos & Macá Tobiano & 6 & 7 & 4.5 & Muy Bueno & & $x$ & $x$ & \\
\hline V04 & PopTour & 0 & 0 & 0 & Sin Calificacion & & $x$ & & $x$ \\
\hline vog & Puelches Turismd & 4 & 7 & 4.3 & Muy Bueno & & $x$ & $x$ & \\
\hline
\end{tabular}

\section{Página Heb enla: 7. Cuenta Verificad,}

\begin{tabular}{|c|c|c|c|c|}
\hline 6. Pág & eb er & 7. Cue & erificad & 7. Observaciones \\
\hline SI & NO & SI & NO & \\
\hline & $x$ & & $x$ & Dirección desactualizada. No posee perfil en dirección actl \\
\hline$x$ & & $x$ & & \\
\hline & $x$ & & $x$ & Posee imágenes pero no relacionadas con la agencia. \\
\hline$x$ & & & $x$ & \\
\hline & $x$ & & $x$ & \\
\hline
\end{tabular}




\section{Resultados}

\section{Alojamiento}

\begin{tabular}{|l|c|c|c|}
\hline 1. Canales de reservas & \\
\hline Booking & Despegar & Otro & Ninguno \\
\hline 12 & 3 & 3 & 4 \\
\hline
\end{tabular}

\begin{tabular}{|l|c|}
\hline \multicolumn{2}{|c|}{ 2. Cantidad de usuarios que votaron } \\
\hline \multicolumn{1}{|c|}{ Intervalo } & Cantidad \\
\hline 1 & 0 \\
\hline 2 & 1 \\
\hline 3 & 1 \\
\hline 4 & 5 \\
\hline 5 & 3 \\
\hline 6 & 8 \\
\hline 7 & 4 \\
\hline
\end{tabular}

\begin{tabular}{|l|c|}
\hline 3. Valoración promedio \\
\hline Intervalo & Cantidad \\
\hline Bueno & 14 \\
\hline Muy Bueno & 8 \\
\hline
\end{tabular}

\begin{tabular}{|c|c|c|c|c|c|}
\hline 4. ¿Posee imágenes? & \multicolumn{2}{c|}{$\begin{array}{c}\text { 5. Imágenes } \\
\text { exteriores }\end{array}$} & \multicolumn{2}{c|}{$\begin{array}{c}\text { 6. Imágenes } \\
\text { interiores }\end{array}$} \\
\hline SI & NO & SI & NO & SI & NO \\
\hline 21 & 1 & 18 & 3 & 20 & 1 \\
\hline
\end{tabular}

\begin{tabular}{|c|c|c|c|}
\hline \multicolumn{2}{|l|}{} & \multicolumn{2}{|c|}{$\begin{array}{c}\text { 8. Página web } \\
\text { enlazada }\end{array}$} \\
\hline S de teléfono añadido & NO & SI & NO \\
\hline 20 & 2 & 10 & 12 \\
\hline
\end{tabular}

\begin{tabular}{|c|c|}
\hline 9. Cuenta Verificada \\
\hline SI & NO \\
\hline 16 & 6 \\
\hline
\end{tabular}




\section{Gastronomía}

\begin{tabular}{|c|c|}
\hline \multicolumn{2}{|c|}{ 2. Cantidad de } \\
usuarios que votaron \\
\hline Intervalo & Cantidad \\
\hline 1 & 1 \\
\hline 2 & 2 \\
\hline 3 & 2 \\
\hline 4 & 4 \\
\hline 5 & 4 \\
\hline 6 & 0 \\
\hline 7 & 5 \\
\hline
\end{tabular}

\begin{tabular}{|c|c|}
\hline \multicolumn{2}{|c|}{$\begin{array}{c}\text { 3. Valoración } \\
\text { promedio }\end{array}$} \\
\hline Intervalo & Cantidad \\
\hline Bueno & 4 \\
\hline $\begin{array}{c}\text { Muy } \\
\text { Bueno }\end{array}$ & 14 \\
\hline
\end{tabular}

\begin{tabular}{|c|c|c|c|c|c|}
\hline \multicolumn{2}{|c|}{$\begin{array}{c}\text { 4. Imágenes } \\
\text { exteriores }\end{array}$} & \multicolumn{2}{c|}{ 5. Imágenes interiores } & \multicolumn{2}{c|}{ 6. Imágenes del Menú } \\
\hline SI & NO & SI & NO & SI & NO \\
\hline 16 & 2 & 17 & 1 & 16 & 2 \\
\hline
\end{tabular}

\begin{tabular}{|l|lll|}
\hline $\begin{array}{l}\text { 7. } \mathbf{N}^{\circ} \\
\text { añadido }\end{array}$ & teléfono & $\begin{array}{l}\text { 8. Página } \\
\text { enlazada }\end{array}$ & Web \\
\cline { 1 - 2 } SI & NO & SI & NO \\
\hline 16 & 2 & 6 & 12 \\
\hline
\end{tabular}

\begin{tabular}{|l|l|}
\hline \multicolumn{2}{|l|}{ 9. Cuenta Verificada } \\
\hline SI & NO \\
\hline 10 & 8 \\
\hline
\end{tabular}




\section{Agencias}

\begin{tabular}{|c|c|}
\hline \multicolumn{2}{|c|}{ 2. Cantidad de } \\
usuarios que votaron \\
\hline Intervalo & Cantidad \\
\hline 7 & 3 \\
\hline
\end{tabular}

\begin{tabular}{|c|c|}
\hline \multicolumn{2}{|c|}{$\begin{array}{c}\text { 3. Valoración } \\
\text { promedio }\end{array}$} \\
\hline Intervalo & Cantidad \\
\hline $\begin{array}{c}\text { Sin } \\
\text { Calificar }\end{array}$ & 3 \\
\hline $\begin{array}{c}\text { Muy } \\
\text { Bueno }\end{array}$ & 2 \\
\hline
\end{tabular}

\begin{tabular}{|c|c|c|c|c|c|}
\hline \multicolumn{2}{|c|}{ 4. ¿Posee imágenes? } & \multicolumn{2}{c|}{$\begin{array}{c}5 . \mathrm{N}^{\circ} \text { de teléfono } \\
\text { añadido }\end{array}$} & \multicolumn{2}{c|}{$\begin{array}{c}\text { 6. Página Web } \\
\text { enlazada }\end{array}$} \\
\hline SI & NO & SI & NO & SI & NO \\
\hline 1 & 4 & 3 & 2 & 2 & 3 \\
\hline
\end{tabular}

\begin{tabular}{|c|c|}
\hline \multicolumn{2}{|c|}{ 7. Cuenta Verificada } \\
\hline SI & NO \\
\hline 1 & 4 \\
\hline
\end{tabular}

